\title{
Colloidal Nanosilica Effect on the Properties and Durability of Coir Reinforced Cement Brick
}

\author{
M. H. S. Hisham Shah, ${ }^{1}$ C. C. Lee $\mathbb{D}^{1},{ }^{1}$ M. Zamzuri, ${ }^{1}$ and V. Vijayan ${ }^{2}{ }^{2}$ \\ ${ }^{1}$ Faculty of Mechanical Engineering Technology, Universiti Malaysia Perlis (UniMAP), Pauh Putra Campus, 02600 Arau, \\ Perlis, Malaysia \\ ${ }^{2}$ Department of Mechanical Engineering, K. Ramakrishnan College of Engineering, Trichy 621112, India \\ Correspondence should be addressed to C. C. Lee; cclee@unimap.edu.my
}

Received 6 January 2022; Revised 28 January 2022; Accepted 29 January 2022; Published 17 February 2022

Academic Editor: Qian Chen

Copyright (C) 2022 M. H. S. Hisham Shah et al. This is an open access article distributed under the Creative Commons Attribution License, which permits unrestricted use, distribution, and reproduction in any medium, provided the original work is properly cited.

\begin{abstract}
The impact of nanosilica on the properties and microstructure of cement-based products has lately attracted a lot of attention. The effects of colloidal nanosilica (CNS) at different concentrations on the hydration process and performance of cement-based composites reinforced with coconut coir were examined in this study. CNS was applied at concentrations of $0 \%, 2 \%, 4 \%$, and $6 \%$ by weight of cement, respectively. The samples were evaluated in terms of flexural test, scanning electron microscopy (SEM), thermogravimetric analysis (TG-DTG), and X-ray Diffraction (XRD) after 7, 28, and 60 days of curing. Flexural strength improved by $13 \%, 11 \%$, and $23 \%$ in the presence of CNS after 7,28 , and 60 days of hydration, respectively, as compared to the samples without CNS addition. The highest flexural strength was reported in samples containing $4 \% \mathrm{CNS}$. Beyond this, flexural strength decreases noticeably owing to the presence of too much nanosilica, which repressed the hydration process. The predominant causes of sample failure appear to be fiber breakage and fiber pull-out. In the sample containing $4 \%$ CNS, a dense structure was seen. The fibers had a strong bond with the matrix, showing that fiber/matrix bonding was improved. CNS served as a pozzolanic reaction promoter, converting $\mathrm{CH}$ to $\mathrm{C}-\mathrm{S}-\mathrm{H}$, and a filler to improve cement microstructure. The $\mathrm{CH}$ content decreased when CNS was added, while the C-S-H gels increased.
\end{abstract}

\section{Introduction}

Concrete is a composite material that is made up of cement as a binding agent. Ordinary Portland cement (OPC) is widely accepted and used in the manufacturing of concrete across the world. As a result, worldwide cement consumption has risen to almost 5 billion metric tonnes [1]. This massive scale of manufacturing requires a lot of energy and releases a lot of carbon dioxide $\left(\mathrm{CO}_{2}\right)$ into the atmosphere [2-5]. As a result, there is an urgent need to reduce the amount of cement used in the concrete industry. Large amounts of industrial waste or by-products, as well as agricultural leftovers, are created as a result of growing levels of industrialization, fast urbanisation, and worldwide food consumption, making disposal difficult. There has been a lot of studies on using these by-products in concrete. Fly ash
(FA), ground granulated blast furnace slag (GGBS), silica fume (SF), rice husk ash (RHA), calcined clay, and other supplementary cementing materials (SCMs) have all been employed as cement substitutes [6-15].

Silica fume has been discovered as the supreme pozzolanic substance, with typical particle sizes ranging from $0.1 \mathrm{~m}$ to $1 \mathrm{~m}$. Silica fume, on the other hand, had a significant tendency to form agglomerates up to several hundred micrometres in diameter, which were difficult to disperse in solution or cement pastes, even with high shear mixing. As a result, SF can remain even after the main hydration processes have stopped $[7,8]$. Providing weak points for crack propagation caused by unreacted SF resulted in loss in mechanical characteristics in the highly substituted mix [9]. Fly ash, a by-product of coal-fired thermal power plants, has been utilized in the making of cement, concrete, and 
geopolymer concrete, among other things. Fly ash has traditionally been utilized in concrete at amounts ranging from $15 \%$ to $25 \%$ by mass of the cementitious material component, with greater levels (30\% to $50 \%)$ employed in major structures (such as foundations and dams) to limit temperature rise [10]. With the addition of fly ash to the mix, the drying shrinkage was minimized. The use of fly ash as a binder lowered the concrete's porosity. As a result, the water sorptivity and chloride permeability of fly ash concrete were decreased $[11,12]$. Granulated blast furnace slag is another common SCM used in cement and concrete. The results showed that increasing the specific surface area of GGBS enhances the splitting tensile strength [14], compressive strength, and hydration activity index [15]. The influence of GGBS on the properties and performance of ultrahigh performance concrete (UHPC) was explored by Ghafari et al. [16] and Yalcinkaya and Copuroglu [17]. It was discovered that lowering the number of tiny pores in UHPC with FA or GGBS reduced autogenous shrinkage [16]. Because GGBS-bearing UHPC is more sensitive to ambient temperature, replacing $60 \%$ of the GGBS reduced cumulative heat emission by $36 \%$ and $28 \%$ at $20^{\circ} \mathrm{C}$ and $35^{\circ} \mathrm{C}$, respectively. The strength difference, on the other hand, is only visible on the first day of curing [17]. Despite the advantages of SCMs replacement or inclusion, most of these SCMs act as fillers and stay inert during the hydration process, resulting in decreased early strength in cement mortar and/or concrete $[11,12,14,15]$. Steam curing, on the other hand, boosted the early age compression strength of metakaolin $(\mathrm{MK})$ included mixtures while limiting late age strength growth, according to Mo et al. [18].

In light of recent advances in nanoscience, the use of nanoadditives in the construction field has opened up new possibilities in cementitious systems [19-23]. Nanosilica (NS) has attracted increased interest and extensive application in cement-based materials due to its nanoscale particle size, high specific surface area, and pozzolanic activity. Powder [24-30] and sol [31, 32] are two common sources of nanosilica. The addition of NS to cement and/or concrete may result in the development of extra hydration products, which aid in the formation of dense microstructure and the strengthening of the bond between aggregate and cement paste, resulting in increased mechanical strength and durability. The specific surface area, micropore volume, and average size of primary particles of the NS were found to impact the slump-flow and mechanical characteristics of cement mortars in research by Quercia et al. [24]. Rong et al. [28] reported a threshold NS concentration of $1.5 \%$, which provided the greatest compressive strength. When compared to regular concrete, the compressive strength of NS modified concrete improves by 16-25\% after 7 days and $12-17 \%$ after 28 days. When cement is substituted by $0.5 \%$ and $1.0 \%$ NS, the bending strength improves by $15.7 \%$ in the crushing stage and by $1.26 \%$ in the failure stage. Furthermore, as compared to the control slab, reinforced slabs with $10 \%$ microsilica and $1 \%$ NS substitution of cement demonstrate higher performance, with compressive strength above the neutral axis of $30.6 \mathrm{MPa}$ and $40.7 \mathrm{MPa}$ at 7 and 28 days, respectively [27]. On the one hand, the NS particles speed up the hydration kinetics, resulting in high early strength, but they also change the rheology of the mixture. The workability of the NS incorporating reveals a significant decline due to the immediate interaction between the NS and the liquid phase of the cementitious mixtures [29, 30]. A reasonable amount of superplasticizer (SP) can be added to avoid the ensuing loss of workability. When the GO and NS content were $0.03 \%$ and $3 \%$, respectively, increasing the SP dose from $0.6 \%$ to $1.2 \%$ resulted in a further reduction in the water sorptivity coefficient of the cement composites [26]. Kong et al. [33, 34] investigated the effects of colloidal silica sol (SS) and nanosilica powder (NS) on fresh and cured cement materials. In comparison to NS addition, the addition of SS had a clearly superior accelerating impact on cement hydration in early age and a better strength enhancement of the mortar in later age. However, following the calcium leaching test, the strength of the mortar with SS addition decreased more than that of the mortar with NS addition, owing to the dissolution of bigger $\mathrm{CH}$ crystals in the coagulated gel network, which resulted in large pores in the mortar. Despite the fact that the flocculation impact of SS may lead to a more compact microstructure [33, 34], cement paste flowability declined when the particle size of SS was reduced, owing to the fact that flocculation inhibited the pozzolanic activity and seeding effect of the nanomaterials [35]. In addition, it was discovered that SS had a greater impact on cement composites with a lower water-cement ratio [36].

The usage of local resources is a crucial consideration when it comes to reducing one's ecological footprint. Natural fiber has been shown to be an effective reinforcement for cement-based materials due to its high tensile strength, high modulus, and low cost. However, despite the advantages of natural fibers, their lifespan in the cement matrix is the main disadvantage of using fiber in cement. Natural fiber will suffer significant deterioration and brittleness when exposed to alkaline pore solution and mineral-rich environment of the cement matrix owing to alkaline hydrolysis and cell wall mineralization. A lot of research on the mechanical strength of natural fiber reinforced cement-based composites, their toughness under various ageing situations, treatment approaches, and partial cement replacement strategies to improve their durability has been published in recent years [37-41]. The incorporation of SCMs that modified the cement matrix proved to slow down both mineralization and alkaline hydrolysis of fiber cell walls by promoting the hydration of cement [41]. By enhancing cement hydration, the introduction of SCMs that affected the cement matrix delayed both mineralization and alkaline hydrolysis of fiber cell walls [41]. However, while most previous research has focused on the performance of cement paste/mortar or concrete, there has been little research on the effect of SS addition on the characteristics and durability of fiber reinforced cement only (without any aggregate and plasticizer). As a result, in this study, the influence of SS at various concentrations on the hydration process and durability of cement-based composites reinforced with coconut coir will be investigated. 


\section{Experimental Procedure}

2.1. Raw Materials. This study employed Type I Portland cement conforming ASTM C150 and Sigma Aldrich's colloidal nanosilica (LUDOX TM-40). Tables 1 and 2 show the chemical compositions of cement and the characteristics of colloidal nanosilica (CNS). Coconut coir was gathered from a neighboring farm.

2.2. Fiber Treatment. Untreated coconut coir (CC) was chopped into $2 \mathrm{~cm}$ lengths prior to treatment. The coir was then rinsed five times in deionized water to eliminate any dirt or impurities. The fibers were then dried for 24 hours in an electric oven at $60^{\circ} \mathrm{C}$. The dried coconut coir was then treated with a $5 \%$ sodium hydroxide $(\mathrm{NaOH})$ solution for 30 minutes at room temperature in order to modify the surface roughness and promote fiber interfacial bonding. Following treatment, the fibers were neutralized with a $5 \%$ acetic acid solution and rinsed with deionized water to eliminate any acid residue from the surface. The treated fibers were then oven-dried for 24 hours at $60^{\circ} \mathrm{C}$.

2.3. Sample Preparation. An automated mortar mixer was used to prepare the cement composite. The samples are prepared using a fixed water-cement ratio of 0.36 and a $10 \%$ coconut coir content derived from the cement weight. CNS was added at a dosage of $0 \%, 2 \%, 4 \%$, and $6 \%$ by weight of cement. CNS was first dispersed and agitated for 1 minute in the mixing water. Before adding the CNS-water solution, the coconut coir and cement were dry-mixed in the mixer for 10 minutes. The fresh mixture was poured into molds as illustrated in Figure 1 after 5 minutes of mixing to make bricks samples with dimensions of $65 \mathrm{~mm} \times 215 \mathrm{~mm} \times 102.5 \mathrm{~mm}$. After 24 hours, the brick samples (Figure 2) were unmolded and cured under open-air condition until the day of testing (7 days, 28 days, and 60 days). A total of 36 samples were made. Table 3 shows the mix proportions for all of the mixtures.

2.4. Testing Procedure. After 7, 28, and 60 days of curing, the brick samples were assessed in terms of flexural test, SEM, TG/DTG, and XRD. The experiment setup of flexural test is shown in Figure 3. The flexural test was performed at room temperature on a Shimadzu Autograph AGS-X machine with a crosshead displacement of $0.5 \mathrm{~mm} / \mathrm{min}$ and a load in the three-point bending setup, according to ASTM C 293-02 standard. A Hitachi TM3000 scanning electron microscope (SEM) was utilized to characterize the microstructure of the sample fracture surface. To improve conductivity, the samples were mounted on stubs and gold coated using a sputter coater.

The TG and DTA curves were obtained using thermogravimetric equipment (Rigaku TG-DTA8122). Hardened bricks were oven-dried at $105^{\circ} \mathrm{C}$, ground to powder, sieved through a 75-mesh sieve, and characterized from ambient temperature to $1000^{\circ} \mathrm{C}$ in a nitrogen environment at a rate of $10^{\circ} \mathrm{C} / \mathrm{min}$. Following the tangent approach suggested by Kocaba [42], the content of calcium hydroxide (CH) was derived from the TG curve. Weight loss due to dehydration of $\mathrm{CH}$ happens in the range of $425^{\circ} \mathrm{C}$ to $550^{\circ} \mathrm{C}$, according to the TG curve. As a result, using the tangent method, the $\mathrm{CH}$ content might be derived from the TG curve. The following equation [36] was used to calculate the quantity of $\mathrm{CH}$ in the system:

$$
\% \mathrm{CH}=\left(\frac{\mathrm{M}_{\mathrm{CH}}}{\mathrm{M}_{\mathrm{H}_{2} \mathrm{O}}}\right) \times \% \operatorname{loss}\left(\mathrm{H}_{2} \mathrm{O}\right),
$$

where $\mathrm{M}_{\mathrm{CH}}$ is the molar weight of $\mathrm{CH}\left(74 \mathrm{~g} \cdot \mathrm{mol}^{-1}\right)$ and $\mathrm{M}_{\mathrm{H} 2 \mathrm{O}}$ is the molar weight of water $\left(18 \mathrm{~g} \cdot \mathrm{mol}^{-1}\right)$.

XRD was used on ground powders with a Rigaku MiniFlex 600 employing CuK (1.5418 ̊) radiation with a current of $15 \mathrm{~mA}$ and a voltage of $40 \mathrm{kV}$ to investigate the constituent and mineralogical changes in the samples that occurred as a result of the addition of varied dosage of CNS. In the angular range of $5-70^{\circ}$ ( $2 \theta$ angle range), the samples were scanned with a step size of $0.02^{\circ}$.

\section{Results and Discussion}

3.1. Flexural Strength. Figure 4 shows the flexural strength of coir reinforced cement bricks with and without CNS addition. Incorporating CNS appears to promote flexural strength, which tends to increase as the amount of CNS increases. However, Santos et al. [43] discovered some contradictions, suggesting that strength dropped as colloidal silica concentration rose. Figure 4 shows that flexural strength increases by $13 \%, 11 \%$, and $23 \%$ after 7,28 , and 60 days of hydration, respectively, as compared to the samples without CNS addition. The strength improvement is attributed to the accelerated effect and the pozzolanic reaction of CNS that consumed $\mathrm{CH}$ to generate $\mathrm{C}-\mathrm{S}-\mathrm{H}$ gel, which results in a densified microstructure, and stronger adhesion between the fiber and matrix of the sample $[34,36,44]$. The benefit of CNS on strength development was more noticeable at dosages greater than $2 \%$. The maximum flexural strength was found in samples with $4 \%$ CNS. Flexural strength decreased noticeably after 4\% CNS replacement in all curing ages. According to prior research, there is an optimal CNS content, beyond which the promoting function is diminished. This might be owing to the presence of too much nanosilica, which repressed the hydration process by captivating the water required for hydration of cement particles in the formation of C-S-H gel [30], resulting in fewer escaped air voids in paste with higher viscosity $[28,45]$.

Figure 4 also shows that while the addition of CNS resulted in better strength compared to the control, the effects of CNS on strength growth are more effective at a later age of curing. The increased flexural strength with curing age was due to further hydration of the system, which provided more hydrates contributing to the strength. Furthermore, due to the high water demand of nanosilica, particularly when relatively high nanosilica dosage levels are examined, cement paste workability was significantly lowered for the selected W/C ratio [29], which slows the reaction at an early 
TABLe 1: Chemical composition of ordinary Portland cement.

\begin{tabular}{|c|c|c|c|c|c|c|c|c|c|}
\hline Chemical composition & $\mathrm{CaO}$ & $\mathrm{SiO}_{2}$ & $\mathrm{Al}_{2} \mathrm{O}_{3}$ & $\mathrm{Fe}_{2} \mathrm{O}_{3}$ & $\mathrm{MgO}$ & $\mathrm{SO}_{3}$ & $\mathrm{~N}_{2} \mathrm{O}$ & LOI & LSF \\
\hline (wt\%) & 64.64 & 21.28 & 5.6 & 3.36 & 2.06 & 2.14 & 0.05 & 0.64 & 0.93 \\
\hline
\end{tabular}

LOI: Loss of ignition; LSF: lime saturation factor.

TABle 2: Properties of colloidal nanosilica.

\begin{tabular}{lc}
\hline Type & LUDOX TM-40 \\
\hline Density & $1.3 \mathrm{~g} / \mathrm{mL}$ \\
Surface area & $140 \mathrm{~m}^{2} / \mathrm{g}$ \\
Concentration & $40 \mathrm{wt} \%$ suspension in $\mathrm{H} 2 \mathrm{O}$ \\
$\mathrm{pH}$ & 9 \\
Average particle size $(\mathrm{nm})$ & $20 \mathrm{~nm}$ \\
\hline
\end{tabular}

age. This finding is in contrast to those published in the literature [32, 46], which claim that CNS has a more obvious strength enhancing impact in the early age because nanosized silica particles may stimulate the early hydration process of cement particles functioning as a nucleation site for C-S-H gel formation. The key cause might be the study's use of a different mix design.

3.2. Microstructure Analysis. The presence of fibers in the cement matrix may improve mechanical qualities like flexural strength. This is due to fiber properties such as high tensile strength, length, and aspect ratio, which allow fiber to act as a bridge across cracks. Despite the aforementioned advantages, the long-term durability of fiber reinforced cement-based composites is limited owing to alkali attack.

Figure 5 depicts SEM micrographs of the fracture surfaces of samples that were cured for 28 days. As noticed from the figure, independent of CNS dosage, two key mechanisms contribute to flexural property degradation: a drop in fiber tensile characteristics, which causes fiber breaking, and a decrease in fiber/matrix interfacial bonding, which causes fiber pull-out. Fiber pull-out appears to be the predominant form of failure, according to the literature $[43,47,48]$. In an alkaline environment, fiber degradation is thought to occur by a peeling-out process, the alkaline hydrolysis, and the deposit of cement hydration product on the fiber. Some hydration product (mainly $\mathrm{CH}$ ) deposits were evident on the surface of coir, as illustrated in Figure 5(a). These deposits cause fiber surface mineralization and loss of elasticity, but no deep mineralization of the fiber was seen. The fracture surface of the fiber at the region of fiber failure in the sample with $2 \%$ CNS shows some necking effect, indicating that fiber failure behaviour remains ductile [48]. For the sample containing $4 \%$ CNS, a dense structure was seen, with only a few fibers pulling out and fiber breaking being the most prominent form of failure. The fibers had a strong bond with the matrix, showing that the fiber/matrix bonding was improved. This discrepancy might be due to CNS's pozzolanic nature. The mobile phases $(\mathrm{CH})$ were promptly consumed and changed into $\mathrm{C}-\mathrm{S}-\mathrm{H}$ hydrates as a result of the pozzolanic reaction, resulting in a dense structure and preventing fiber mineralization. Shrinkage cracks formed over $4 \%$ CNS (threshold content), with fiber pull-out being the most prominent failure mode due to poor/matrix bonding (Figure $5(\mathrm{~d})$ ). These observations are in line with the flexural strength findings.

3.3. Amount of $\mathrm{CH}$. TGA was utilized to investigate the effect of CNS on changes in microstructure composition. The DTA/TGA curves showed three primary endothermic peaks. As documented in the literature $[2,28,44,46]$, endothermic peaks in the range of $60-300^{\circ} \mathrm{C}$ are caused by the loss of free water and dehydration of water molecules linked with ettringite (AFt) and/or C-S-H. Furthermore, weight loss between 400 and $500^{\circ} \mathrm{C}$ is due to dehydration of $\mathrm{CH}$, whereas thermal deterioration between 600 and $800^{\circ} \mathrm{C}$ is due to decarbonation of calcium carbonate. All four samples were analyzed at different curing periods, and the $\mathrm{CH}$ content computed based on the weight loss of the second peak is shown in Table 4. The result shows that adding CNS resulted in an increased reduction of $\mathrm{CH}$ content; with increasing CNS dose, a considerable reduction of $\mathrm{CH}$ content was seen. When compared to the control sample, the $\mathrm{CH}$ content in the sample is reduced by $19.6 \%$ and $12.6 \%$ by incorporating $2 \% \mathrm{CNS}$, and by $33 \%$ and $26.8 \%$ by incorporating 4\% CNS at 7 days and 28 days of curing, respectively. The consumption of $\mathrm{CH}$ via the pozzolanic reaction of CNS, which produces $\mathrm{C}-\mathrm{S}-\mathrm{H}$ gel, can be ascribed to the reduction of $\mathrm{CH}[2,44,45]$. This is consistent with the considerable rise in flexural strength mentioned in Section 3.1. It is worth noting that while $\mathrm{CH}$ reduction increases with increasing CNS incorporation (up to $4 \% \mathrm{CNS}$ ), the $\mathrm{CH}$ content continues to rise in the $2 \%$ and $4 \%$ CNS samples at 28 days of curing, implying slowed $\mathrm{CH}$ generation and cement hydration on the one hand, and a longer curing age and lower $\mathrm{CH}$ content due to the fact that $\mathrm{CH}$ is continuously consumed by the pozzolanic reaction of CNS on the other hand. As a result, a longer curing age results in more C-S-H gel, which is consistent with Liu et al. [44]. Those without CNS and samples with excessive CNS (6\%), on the other hand, showed the opposite results. It is also worth noting that there was no additional deflection in $\mathrm{CH}$ after 4\% CNS dose, suggesting that CNS dosages higher than $4 \%$ may not be beneficial in hydration activities.

3.4. XRD Analysis. Figure 6 shows the peaks of AFt, $\mathrm{CH}$ in the form of portlandite, C-S-H, calcite, and unhydrated content of $\mathrm{C}_{2} \mathrm{~S}$ and $\mathrm{C}_{3} \mathrm{~S}$ for samples with and without CNS incorporation at 7 and 28 days, respectively. There are no new phases in the microstructure. The main peak of C-S-H $\left(29.5^{\circ}\right)$ coincides with the main peaks of calcite $\left(\mathrm{CaCO}_{3}\right)$ and calcium oxide $(\mathrm{CaO})$, regardless of CNS content or curing age. The existence of weakly crystallized calcite was corroborated by diffuse peaks at $42.92^{\circ}, 47.3^{\circ}$, and $48.2^{\circ}$, which were identical to those reported by Tonoli et al. [49]. The presence of CNS in the samples accentuated the peak of C-S- 

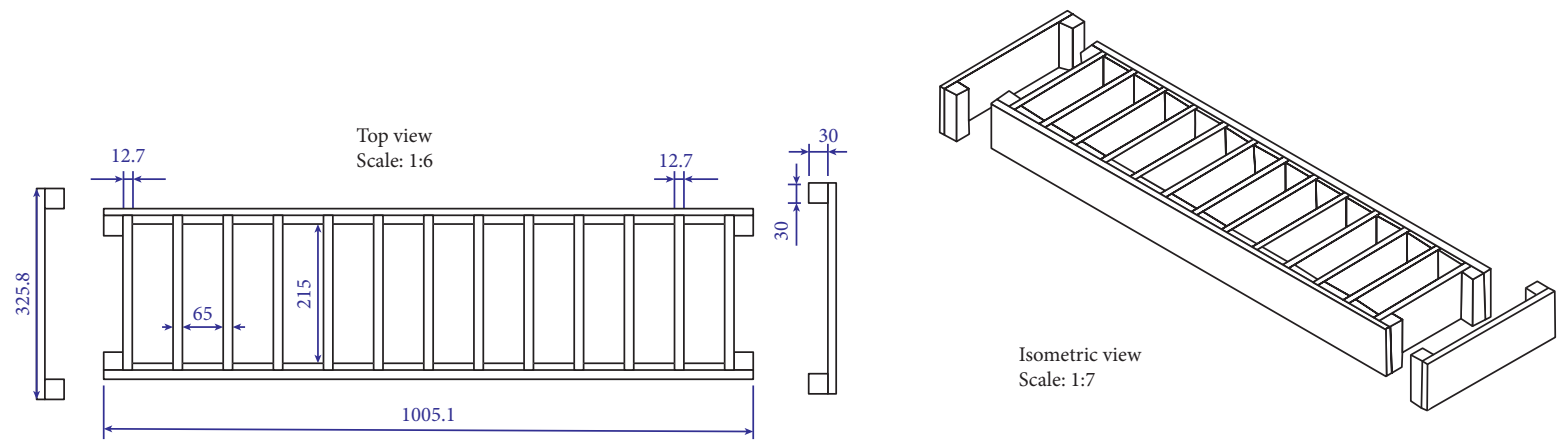

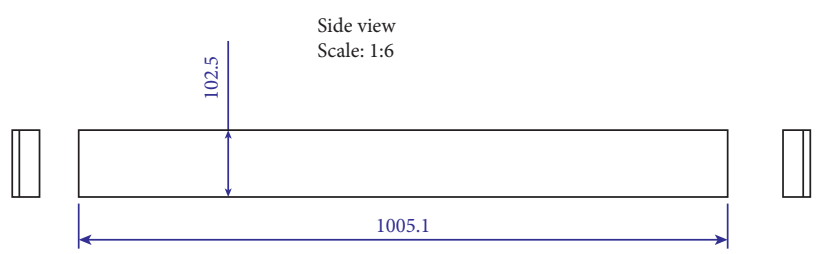

Figure 1: Wooden mold for brick fabrication.

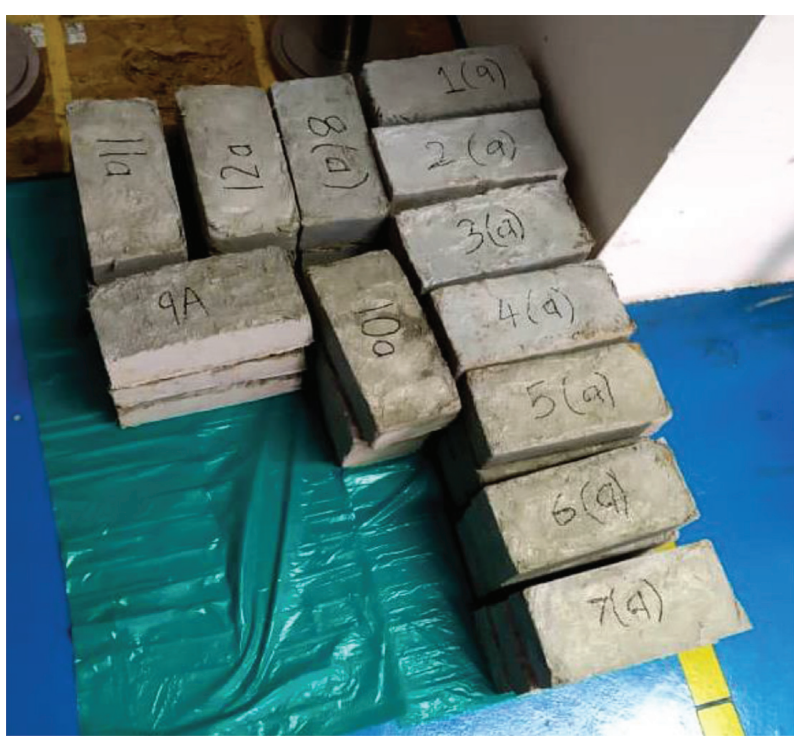

Figure 2: Brick samples of different CNS content.

TABLE 3: Mix proportions of the samples.

\begin{tabular}{|c|c|c|c|c|c|c|}
\hline Cement (g) & Water $(\mathrm{mL})$ & Fiber (wt $\%)$ & CNS (wt\%) & \multicolumn{3}{|c|}{ Sample } \\
\hline \multirow[t]{4}{*}{2000} & 720 & 10 & 0 & $7 \mathrm{D}$ & $28 \mathrm{D}$ & $60 \mathrm{D}$ \\
\hline & & & 2 & $7 \mathrm{D}$ & $28 \mathrm{D}$ & $60 \mathrm{D}$ \\
\hline & & & 4 & $7 \mathrm{D}$ & $28 \mathrm{D}$ & $60 \mathrm{D}$ \\
\hline & & & 6 & $7 \mathrm{D}$ & $28 \mathrm{D}$ & $60 \mathrm{D}$ \\
\hline
\end{tabular}

$\mathrm{H}$ while substantially reducing the peak of $\mathrm{CH}$, as seen in the figure, which is consistent with the TG finding. At 7 and 28 days, the intensity of $\mathrm{CH}$ peaks decreased as the degree of CNS content increased, relative to samples without CNS.
This suggests that CNS has a high activity, promoting the interaction between $\mathrm{CH}$ and pozzolanic material. Among the CNS incorporation samples, the sample comprising $4 \%$ CNS had a greater C-S-H intensity and a lower $\mathrm{CH}$ peak. As 


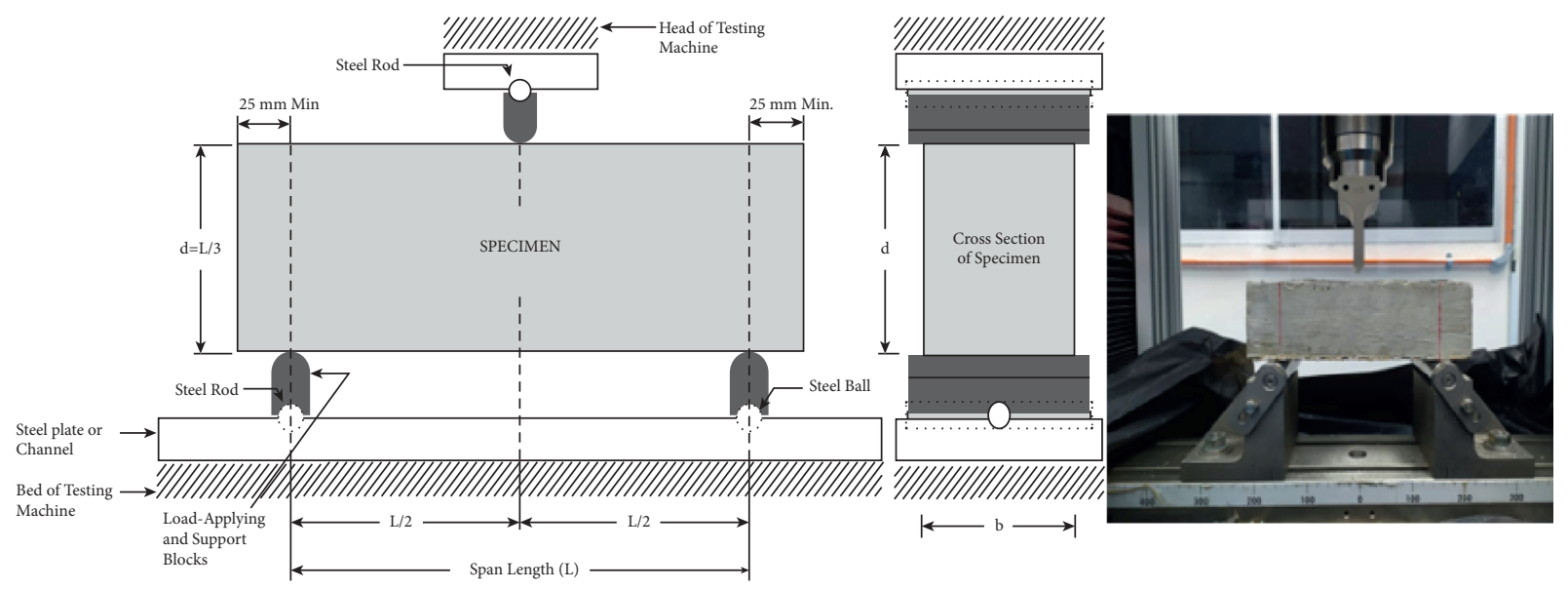

Figure 3: Experiment setup of flexural test.

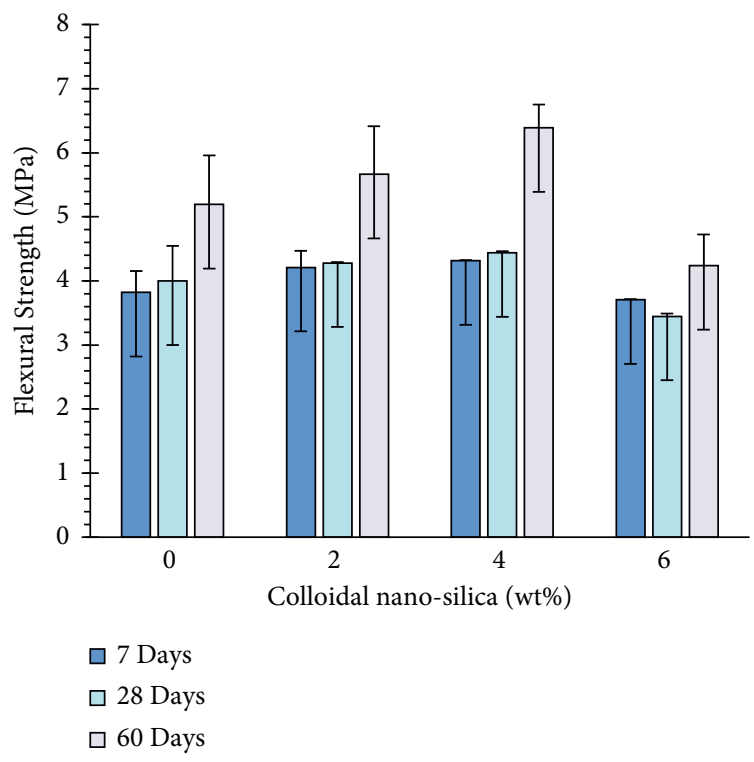

Figure 4: Flexural strength of samples with different CNS content.

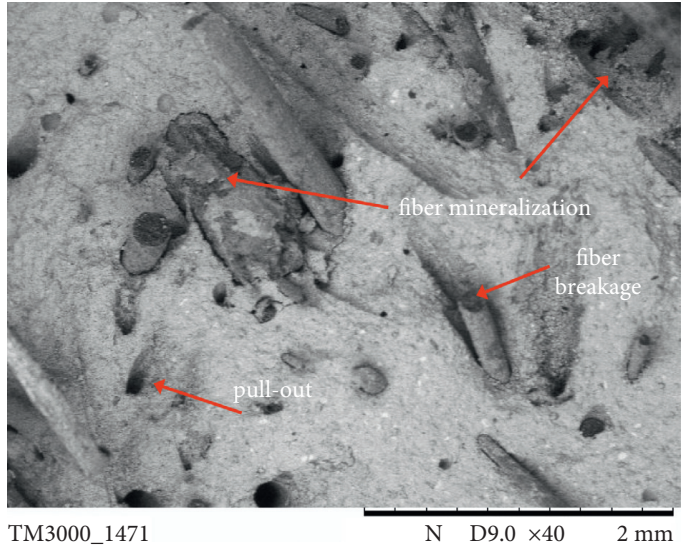

(a)

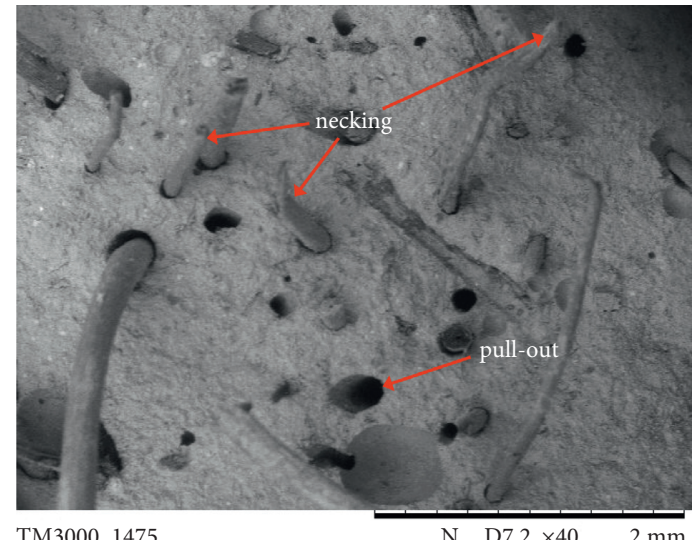

(b)

Figure 5: Continued. 


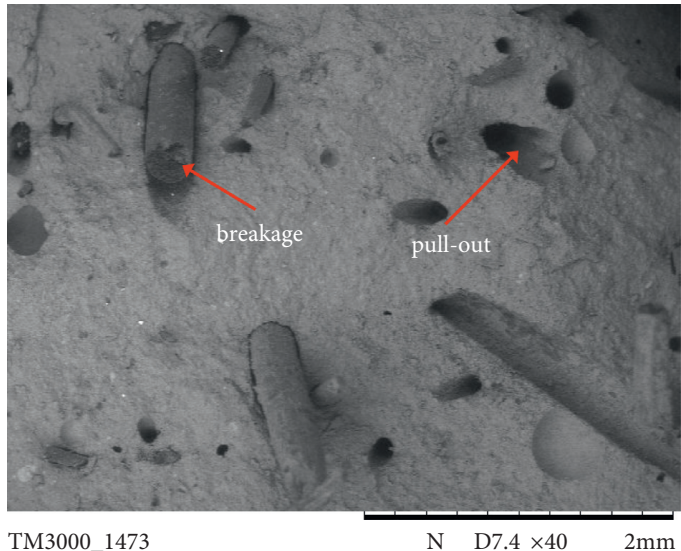

(c)

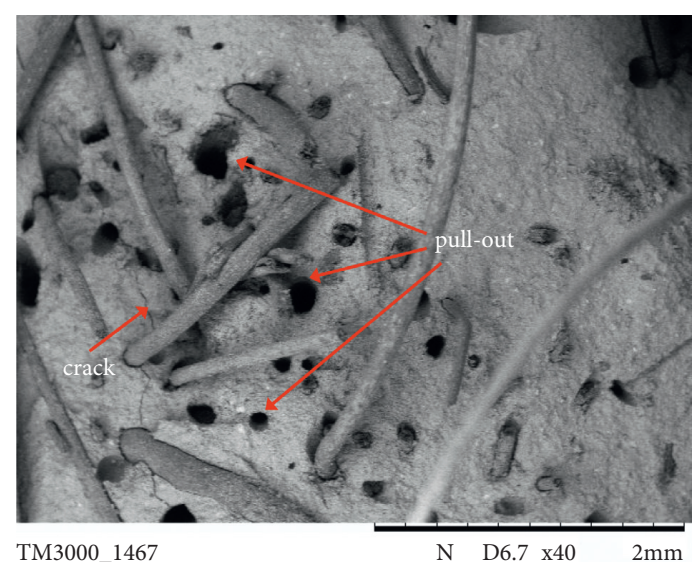

(d)

FIGURE 5: SEM observation of the fracture surface of samples: (a) without CNS and with (b) 2\%, (c) 4\%, and (d) 6\% CNS.

TABLE 4: CH content of samples with different CNS content by thermogravimetric analysis.

\begin{tabular}{lccc}
\hline Sample & & CH (\%) & \\
& 7 days & 28 days & 60 days \\
\hline $0 \%$ CNS & 7.36 & 7.24 & 8.47 \\
$2 \%$ CNS & 5.92 & 6.33 & 6.13 \\
$4 \%$ CNS & 4.93 & 5.30 & 4.69 \\
$6 \%$ CNS & 6.74 & 6.66 & 7.15 \\
\hline
\end{tabular}

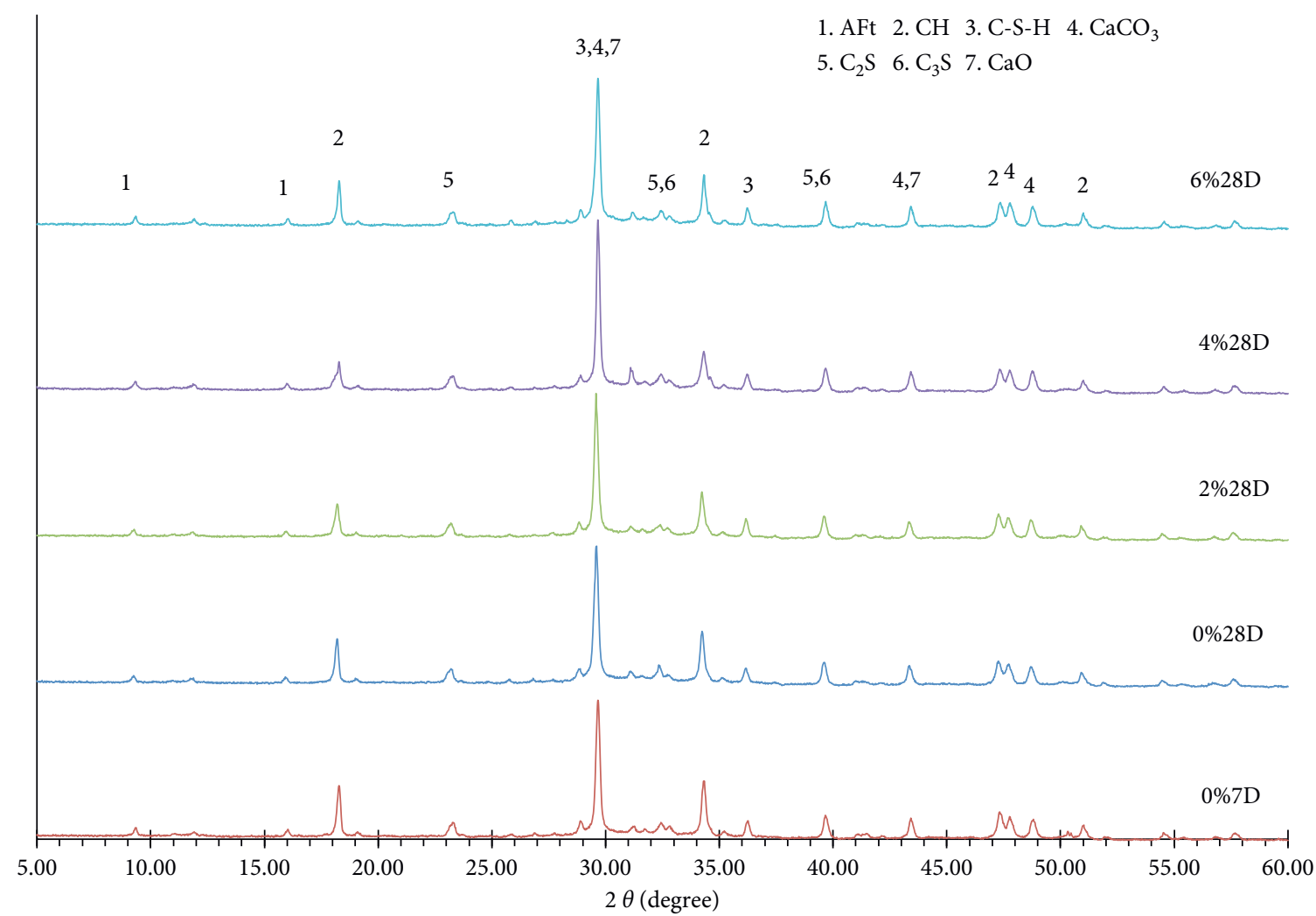

FIGURE 6: XRD patterns of the samples after being cured for 7 days and 28 days. 
a result, the interfacial bonding strength between the coir fiber and the matrix is stronger in the $4 \%$ CNS sample than in the others. The partial carbonation of $\mathrm{CH}$ and $\mathrm{C}-\mathrm{S}-\mathrm{H}$ was ascribed to the existence of calcite. There were no noticeable changes in $\mathrm{AFt}, \mathrm{C}_{2} \mathrm{~S}$, or $\mathrm{C}_{3} \mathrm{~S}$.

\section{Conclusions}

The effects of CNS incorporation on the properties of coircement bricks at various dosages and curing ages were investigated in this study, and the following result was reached:

(1) As the dosage of CNS incorporation was raised, the flexural strength rose. After 28 days of curing, incorporating $4 \% \mathrm{CNS}$ resulted in a greater strength of 6.39 $\mathrm{MPa}$. Beyond this, flexural strength decreases noticeably owing to the presence of too much nanosilica, which repressed the hydration process.

(2) Fiber breakage and fiber pull-out appear to be the predominant form of samples failure. A dense structure was seen in the sample comprising $4 \%$ CNS. The fibers exhibited a strong connection with the matrix, indicating better fiber/matrix bonding.

(3) Adding CNS resulted in an increased reduction of $\mathrm{CH}$ content. There was no additional deflection in $\mathrm{CH}$ after $4 \% \mathrm{CNS}$ dose, suggesting that CNS dosages higher than $4 \%$ may not be beneficial in hydration activities.

(4) CNS acted as a promoter of pozzolanic reaction by transforming $\mathrm{CH}$ into $\mathrm{C}-\mathrm{S}-\mathrm{H}$, as well as a filler to enhance cement microstructure. With the addition of CNS, the $\mathrm{CH}$ content reduced and the C-S-H gels rose.

\section{Data Availability}

The data employed to support the study's results are provided in the article. If further data or information are needed, the corresponding author can provide it upon request.

\section{Conflicts of Interest}

The authors state that the publishing of this work does not include any conflicts of interest.

\section{Acknowledgments}

The authors are thankful to the Ministry of Higher Education (KPT) for financing this study through the Fundamental Research Grant Scheme (FRGS) with grant number FRGS/1/2018/TK05/UNIMAP/02/4.

\section{References}

[1] A. N. Reddy, "An experimental study on effect of colloidal nano-silica on tetranary blended concrete," Advances in Concrete Construction, vol. 7, no. 2, pp. 107-115, 2019.

[2] M. Aly, M. S. J. Hashmi, A. G. Olabi, M. Messeiry, E. F. Abadir, and A. I. Hussain, "Effect of colloidal nano-silica on the mechanical and physical behaviour of waste-glass cement mortar," Materials \& Design, vol. 33, pp. 127-135, 2012.

[3] A. Narender Reddy and T. Meena, "A study on compressive behavior of ternary blended concrete incorporating alccofine," Materials Today Proceedings, vol. 5, no. 5, pp. 11356-11363, 2018.

[4] K. V. Teja, P. P. Sai, and T. Meena, "Investigation on the behaviour of ternary blended concrete with SCBA and SF," IOP Conference Series: Materials Science and Engineering, vol. 263, no. 3, p. 032012, 2017.

[5] L. K. Turner and F. G. Collins, "Carbon dioxide equivalent (CO2-e) emissions: a comparison between geopolymer and OPC cement concrete," Construction and Building Materials, vol. 43, pp. 125-130, 2013.

[6] V. T. Giner, S. Ivorra, F. J. Baeza, E. Zornoza, and B. Ferrer, "Silica fume admixture effect on the dynamic properties of concrete," Construction and Building Materials, vol. 25, no. 8, pp. 3272-3277, 2011.

[7] D. R. G. Mitchell, I. Hinczak, and R. A. Day, "Interaction of silica fume with calcium hydroxide solutions and hydrated cement pastes," Cement and Concrete Research, vol. 28, no. 11, pp. 1571-1584, 1998.

[8] V. G. Papadakis, "Experimental investigation and theoretical modeling of silica fume activity in concrete," Cement and Concrete Research, vol. 29, no. 1, pp. 79-86, 1999.

[9] N. Y. Mostafa, Q. Mohsen, S. A. S. El-Hemaly, S. A. ElKorashy, and P. W. Brown, "High replacements of reactive pozzolan in blended cements: microstructure and mechanical properties," Cement and Concrete Composites, vol. 32, no. 5, pp. 386-391, 2010.

[10] M. Thomas, "Optimizing the use of fly ash in concrete," 2007, https://www.cement.org/docs/default-source/fc_concrete_ technology/is548-optimizing-the-use-of-fly-ash-concrete.pdf.

[11] S. Sahoo, B. B. Das, and S. Musta, "Acid, alkali and chloride resistance of concrete composed of low carbonated fly ash," Journal of Materials in Civil Engineering, vol. 29, no. 3, pp. 1-12, 2017.

[12] A. K. Saha, "Effect of class F fly ash on the durability properties of concrete," Sustainable Environment Research, vol. 28, no. 1, pp. pp25-31, 2018.

[13] S. Saha and C. Rajasekaran, "Mechanical properties of recycled aggregate concrete produced with Portland pozzolana cement," Advances in Concrete Construction, vol. 4, no. 1, pp. 27-35, 2016.

[14] X. M. Zhou, J. R. Slater, S. E. Wavell, and O. Oladiran, "Effects of PFA and GGBS on early-ages engineering properties of Portland cement systems," Journal of Advanced Concrete Technology, vol. 10, no. 2, pp. 74-85, 2012.

[15] J. Dai, Q. Wang, C. Xie, Y. Xue, Y. Duan, and X. Cui, “The effect of fineness on the hydration activity index of ground granulated blast furnace slag," Materials, vol. 12, no. 18, Article ID 2984, 2019.

[16] E. Ghafari, S. A. Ghahari, H. Costa, E. Júlio, A. Portugal, and L. Durães, "Effect of supplementary cementitious materials on autogenous shrinkage of ultra-high performance concrete," Construction and Building Materials, vol. 127, pp. 43-48, 2016.

[17] C. Yalcinkaya and O. Copuroglu, "Hydration heat, strength and microstructure characteristic of UHPC containing blast furnace slag," Journal of Building Engineering, vol. 34, Article ID 101915, 2021.

[18] Z. Mo, X. Gao, and A. Su, "Mechanical performances and microstructures of metakaolin contained UHPC matrix under steam curing conditions," Construction and Building Materials, vol. 268, Article ID 121112, 2021. 
[19] A. Khitab and M. T. Arshhad, "Nano construction materials: A review," Reviews on Advanced Materials Science, vol. 38, pp. 181-189, 2014.

[20] M. S. M. Norhasri, M. S. Hamidah, and A. M. Fadzil, "Applications of using nano material in concrete: a review," Construction and Building Materials, vol. 133, no. 15, pp. 91-97, 2017.

[21] P. Karthigai Priya and S. Vanitha, "Effect of nano silica on the properties of concrete and mortar - a state of art," International Review of Applied Sciences and Engineering, vol. 13, no. 1, pp. 70-79, 2021.

[22] L. Li, Q. Zheng, X. Wang, B. Han, and J. Ou, "Modifying fatigue performance of reactive powder concrete through adding pozzolanic nanofillers," International Journal of Fatigue, vol. 156, Article ID 106681, 2022.

[23] B. Zhang, X. Zhang, Y. Li, M. Hao, and J. Liu, "Dynamic inversion analysis of structural layer modulus of semirigid base pavement considering the influence of temperature and humidity," Advances in Civil Engineering, vol. 2020, Article ID 8899888, 12 pages, 2020.

[24] G. Quercia, A. Lazaro, J. W. Geus, and H. J. H. Brouwers, "Characterization of morphology and texture of several amorphous nano-silica particles used in concrete," Cement and Concrete Composites, vol. 44, pp. 77-92, 2013.

[25] S. Kawashima, P. Hou, D. J. Corr, and S. P. Shah, "Modification of cement-based materials with nanoparticles," Cement and Concrete Composites, vol. 36, pp. 8-15, 2013.

[26] M. Newell and E. Garcia-Taengua, "Fresh and hardened state properties of hybrid graphene oxide/nanosilica cement composites," Construction and Building Materials, vol. 221, pp. 433-442, 2019.

[27] R. Kancharla, V. R. Maddumala, T. V. N. Prasanna, L. Pullagura, R. R. Mukiri, and M. V. Prakash, "Flexural behavior performance of reinforced concrete slabs mixed with nano- and microsilica," Journal of Nanomaterials, vol. 2021, Article ID 1754325, 11 pages, 2021.

[28] Z. Rong, W. Sun, H. Xiao, and G. Jiang, "Effects of nano-SiO2 particles on the mechanical and microstructural properties of ultra-high performance cementitious composites," Cement and Concrete Composites, vol. 56, pp. 25-31, 2015.

[29] M. Berra, F. Carassiti, T. Mangialardi, A. E. Paolini, and M. Sebastiani, "Effects of nanosilica addition on workability and compressive strength of Portland cement pastes," Construction and Building Materials, vol. 35, pp. 666-675, 2012.

[30] F. Lavergne, R. Belhadi, J. Carriat, and A. Ben Fraj, "Effect of nano-silica particles on the hydration, the rheology and the strength development of a blended cement paste," Cement and Concrete Composites, vol. 95, pp. 42-55, 2019.

[31] F. Kontoleontos, P. E. Tsakiridis, A. Marinos, V. Kaloidas, and M. Katsioti, "Influence of colloidal nanosilica on ultrafine cement hydration: physicochemical and microstructural characterization," Construction and Building Materials, vol. 35, pp. 347-360, 2012.

[32] P. Hou, S. Kawashima, D. Kong, D. J. Corr, J. Qian, and S. P. Shah, "Modification effects of colloidal nanoSiO ${ }_{2}$ on cement hydration and its gel property," Composites Part B, vol. 45, pp. 400-448, 2013.

[33] D. Kong, D. J. Corr, P. Hou, Y. Yang, and S. P. Shah, "Influence of colloidal silica sol on fresh properties of cement paste as compared to nano-silica powder with agglomerates in micron-scale," Cement and Concrete Composites, vol. 63, pp. 30-41, 2015.

[34] D. Kong, H. Pan, L. Wang et al., "Effect and mechanism of colloidal silica sol on properties and microstructure of the hardened cement-based materials as compared to nanosilica powder with agglomerates in micron-scale," Cement and Concrete Composites, vol. 98, pp. 137-149, 2019.

[35] X. Zhang, H. Yang, Q. Yang, X. Du, C. Li, and X. Cheng, "Effects of particles size of colloidal nanosilica on hydration of Portland cement at early age," Advances in Mechanical Engineering, vol. 11, no. 2, pp. 1-9, 2019.

[36] H. Du and S. D. Pang, "High performance cement composites with colloidal nano-silica," Construction and Building Materials, vol. 224, pp. 317-325, 2019.

[37] O. Onuaguluchi and N. Banthia, "Plant-based natural fibre reinforced cement composites: a review," Cement and Concrete Composites, vol. 68, pp. 96-108, 2016.

[38] S. N. Zatul, S. S. Kim, and A. S. Zuruzi, "Fiber treatment and loading affect mechanical properties of bamboo/cement composite," International Journal of Advances in Agricultural and Environmental Engineering, vol. 4, pp. 19-22, 2017.

[39] M. Ramli, W. H. Kwan, and N. F. Abas, "Strength and durability of coconut-fiber-reinforced concrete in aggressive environments," Construction and Building Materials, vol. 38, pp. 554-566, 2013.

[40] M. Khorami and E. Ganjian, "The effect of limestone powder, silica fume and fibre content on flexural behaviour of cement composite reinforced by waste Kraft pulp," Construction and Building Materials, vol. 46, pp. 142-149, 2013.

[41] J. Wei, S. Ma, and D. S. G. Thomas, "Correlation between hydration of cement and durability of natural fiber-reinforced cement composites," Corrosion Science, vol. 106, pp. 1-15, 2016.

[42] V. Kocaba, "Development and evaluation of methods to follow microstructural development of cementitious systems including slags," Ph. D Thesis, École Polytechnique Fédérale De Lausanne, Lausanne, Switzerland, 2009.

[43] S. F. Santos, J. d. A. Rodrigues, G. H. D. Tonoli, A. E. F. d. S. Almeida, and H. Savastano, "Effect of colloidal silica on the mechanical properties of fiber-cement reinforced with cellulosic fibers," Journal of Materials Science, vol. 49, no. 21, pp. 7497-7506, 2014.

[44] X. Liu, B. Ma, H. Tan et al., "Effects of colloidal nano- $\mathrm{SiO}_{2}$ on the immobilization of chloride ions in cement-fly ash system," Cement and Concrete Composites, vol. 110, Article ID 1033596, 2020.

[45] R. Yu, P. Spiesz, and H. J. H. Brouwers, "Effect of nano-silica on the hydration and microstructure development of ultrahigh performance concrete (UHPC) with a low binder amount," Construction and Building Materials, vol. 65, pp. 140-150, 2014.

[46] K. Snehal, B. B. Das, and M. Akanksha, "Early age, hydration, mechanical and microstructure properties of nano-silica blended cementitious composites," Construction and Building Materials, vol. 233, Article ID 117212, 2020.

[47] V. Sabatheir, C. Magniont, G. Escadeillas, and C. A. Juarez, "Flax and hemp fibre reinforced pozzolanic matrix:evaluation of impact of time and natural weathering," European Journal of Environmental and Civil Engineering, vol. 21, no. 11, pp. 1403-1417, 2017.

[48] B. J. Mohr, H. Nanko, and K. E. Kurtis, "Durability of kraft pulp fiber-cement composites to wet/dry cycling," Cement and Concrete Composites, vol. 27, no. 4, pp. 435-448, 2005.

[49] G. H. D. Tonoli, S. F. Santos, H. Savastano, S. Delvasto, R. Mejía de Gutiérrez, and M. d. M. Lopez de Murphy, "Effects of natural weathering on microstructure and mineral composition of cementitious roofing tiles reinforced with fique fibre," Cement and Concrete Composites, vol. 33, no. 2, pp. 225-232, 2011. 